\title{
Deforestation: An Implication of High Rate of Unemployed and Low-Income Household Members in Rural Communities in Kebbi, Nigeria.
}

\author{
Uba Matthew Ndubuisi
}

10 December, 2021

\section{Contents}

2.0 METHODOLOGY 5

2.1 Description of Data ... . . . . . . . . . . . . . . . . . . . . . . . . .

2.2 Method of Data Collection . . . . . . . . . . . . . . . . . . . . . 6

2.3 Method of Data Analysis . . . . . . . . . . . . . . . . . . . . . 6

3.0 RESULTS AND DISCUSSIONS
7

$\begin{array}{ll}4.0 \text { CONCLUSION } & 17\end{array}$

5.0 REFERENCE
18

Author: Uba Matthew Ndubuisi

(M. Sc.) Environmental Science - Global Change and Sustainability

Thanks: Professor Gaetan Carlo

Affiliation: Department of Environmental Science, Informatics and Statistics

Ca'Foscari University of Venice, Venezia (VE), Italy (IT).

\begin{abstract}
Deforestation has been a major environmental issue in Northern Nigeria and despite several advocacy, yet such practice has continued to endure. Apart from identifying the courses of deforestation which are well pronounced and evident, yet there are uncovered root courses of deforestation which are major factors and highly devastating. These factors are unemployment and low-income among households in Northern Nigeria. As a result of low social/financial status of the household, they could not subscribe to the use of other sources of energy for their domestic and commercial activities rather they depend highly on cutting down trees to make fuel wood (firewood) and charcoal (gotten from burnt wood) for the source of energy for their domestic and commercial activities. This was proven by the analysis of a secondary dataset using R-Programming, sourced from the World Bank Microdata Library, a survey carried out in 2015 in Kebbi, Nigeria titled Nigeria-Feed the Future Livelihood Project 2015, Baseline Survey worldbank.org. The dataset contains 3976 households observed and 296 values were found missing which resulted to analyzing 3758 household after the missing values were omitted. Variables describing the employed members of the household, energy sources for lighting fuel and energy sources for cooking fuel for the households were
\end{abstract}


extracted from the secondary dataset. Results revealed from the histogram revealed that there are over 3000 households dependent on fuel wood as an energy source. Also, results from the Analysis of Variance (ANOVA) revealed that annual income of the households has significant impact on cooking fuel sources $(0.0104<0.05)$ and has a very strong significance on lighting fuel sources $(0.000<0.05)$. The low-income rate of households was evident showing the relationship between employed members of the households with a very strong significance on annual income of the households $(0.000375<0.05)$. This revealed that unemployed members of the households results to low-income of the households in Kebbi make them to highly depend on the use of fuel wood (firewood) and charcoal (gotten from burnt wood) on a dialy bases as a source of energy for cooking and lighting fuel. They also export and sell fuel wood and charcoal for financial gain to neighboring countries.

Keywords: Deforestation, Fuel Wood (Firewood), Charcoal, Household, Employed Members, Annual Income, Cooking Fuel Source, Lighting Fuel Source.

\subsection{INTRODUCTION}

Deforestation is the transformation of forestland to non-forest land which can be described as clearing of forest (Hasan, 2020). It is propelled by certain factors such as agriculture, population growth and urbanization, logging, conflict and grazing, fuel wood (firewood) collection, mining activities, pollution, and desertification (Habila, 2018).

Of all energy requirement, wood is made up of $58 \%$, and in Nigeria, demand for wood supplies exceeds the growth rate. Eighty million (80 million) cubic meters of fuel wood is currently used in Nigeria annually for domestic and commercial activities.

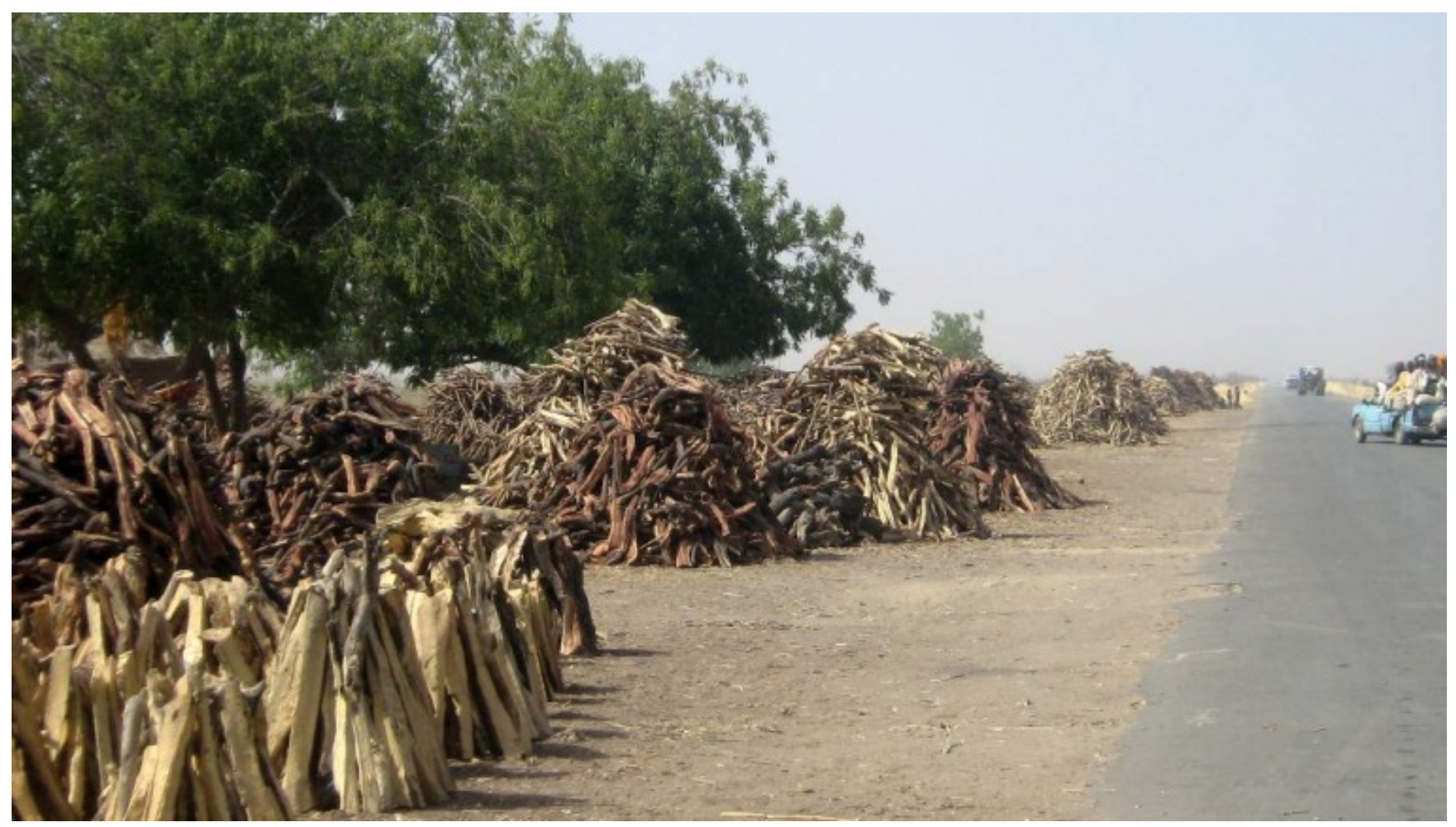




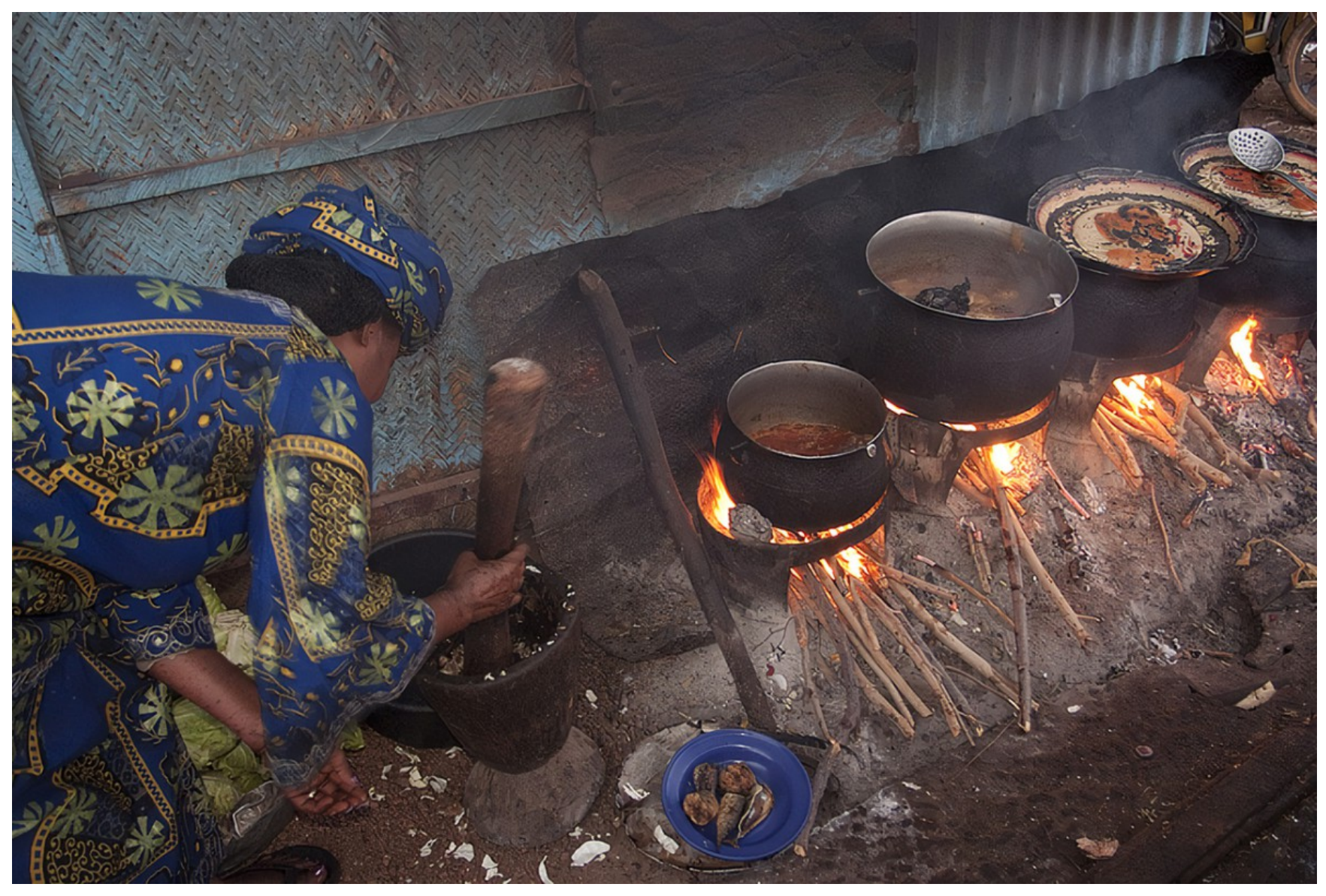

Figure 1.0: Fuel Wood and its use in domestic and commercial purpose

Recent records revealed that fuel wood consumption rate was given as 23.3 million cubic meters per year in Northern Nigeria (Adewunmi, 2018). Several researchers have identified poverty as a factor that determine choice of energy source for domestic and commercial use as a reason for over rely on fuel wood and charcoal (formed when wood is burnt, and it is used for ironing, black smith etc..) by most household in Nigeria. Reports also revealed that a reasonable percentage of low- and middle-income urban dwellers use charcoal as an alternative to domestic energy needs (Patrick, 2013). Fuel wood and charcoal are not only for domestic uses but also a source for household income (Aboh \& Zhangqi, 2016). 


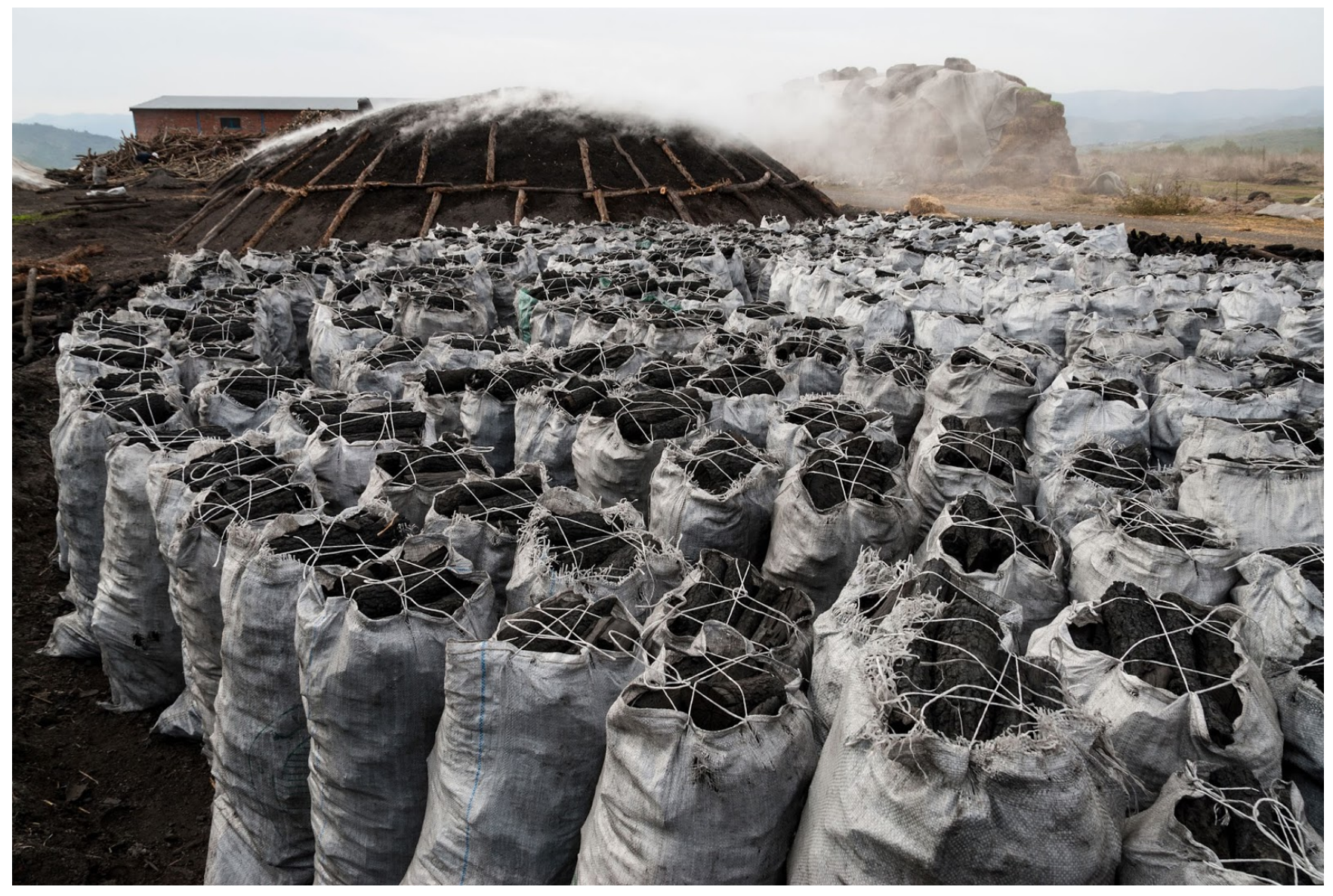




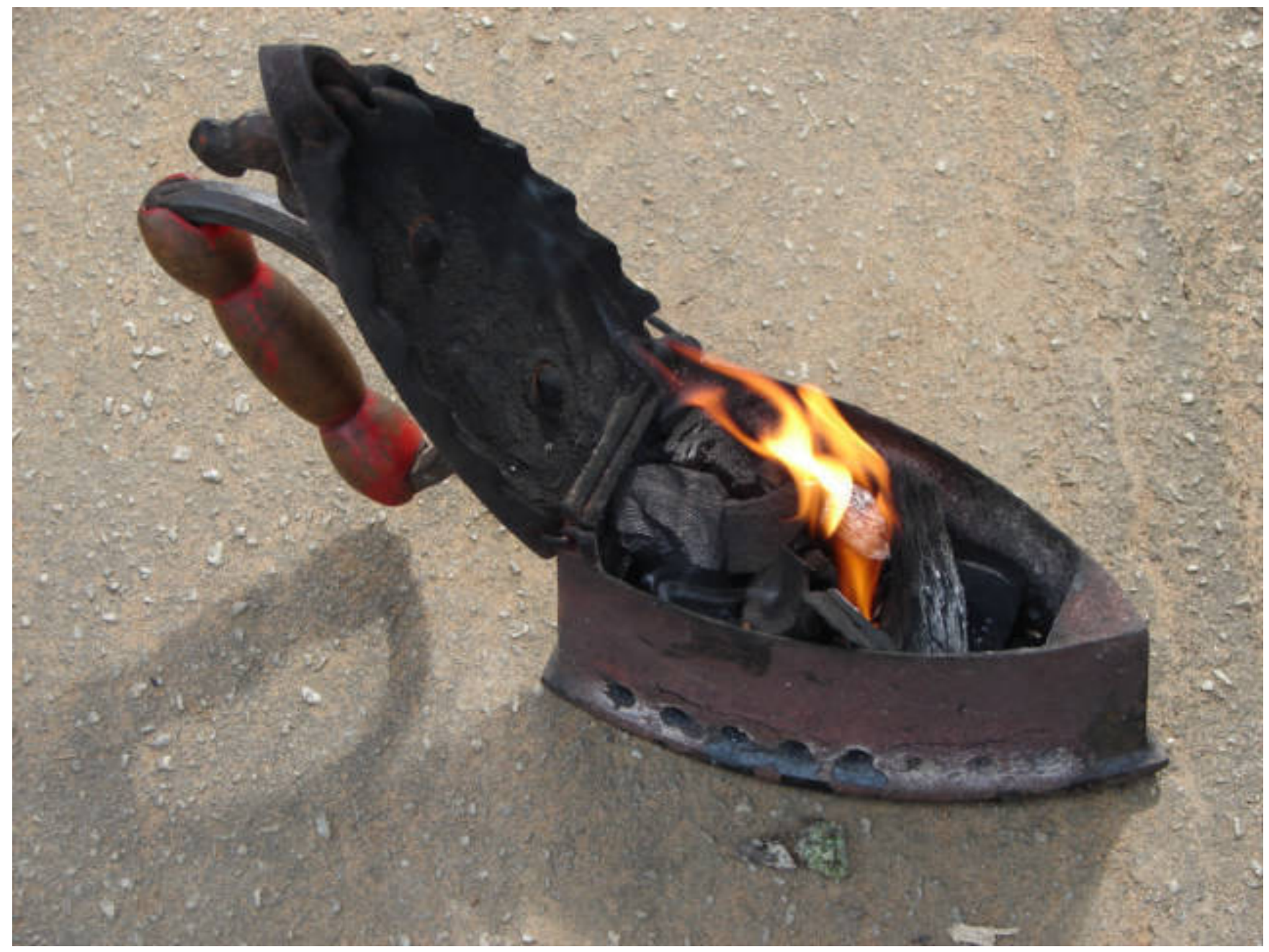

Figure 2.0: Charcoal from burnt wood use for ironing and prepared for export

Therefore, this research is to analyze the impact of unemployed and low-income household members on deforestation in Nigeria, a case study of Kebbi.

\subsection{METHODOLOGY}

\subsection{Description of Data}

Secondary dataset (ftfnlp_baseline_publish_06142017.csv) were sourced from the World Bank Microdata Library, a survey carried out in 2015 in Kebbi, Nigeria title Nigeria - Feed the Future Nigeria Livelihoods Project 2015, Baseline Survey (worldbank.org). Source: https://microdata.worlbank.org/index.php/catalog/2935/get.microd 


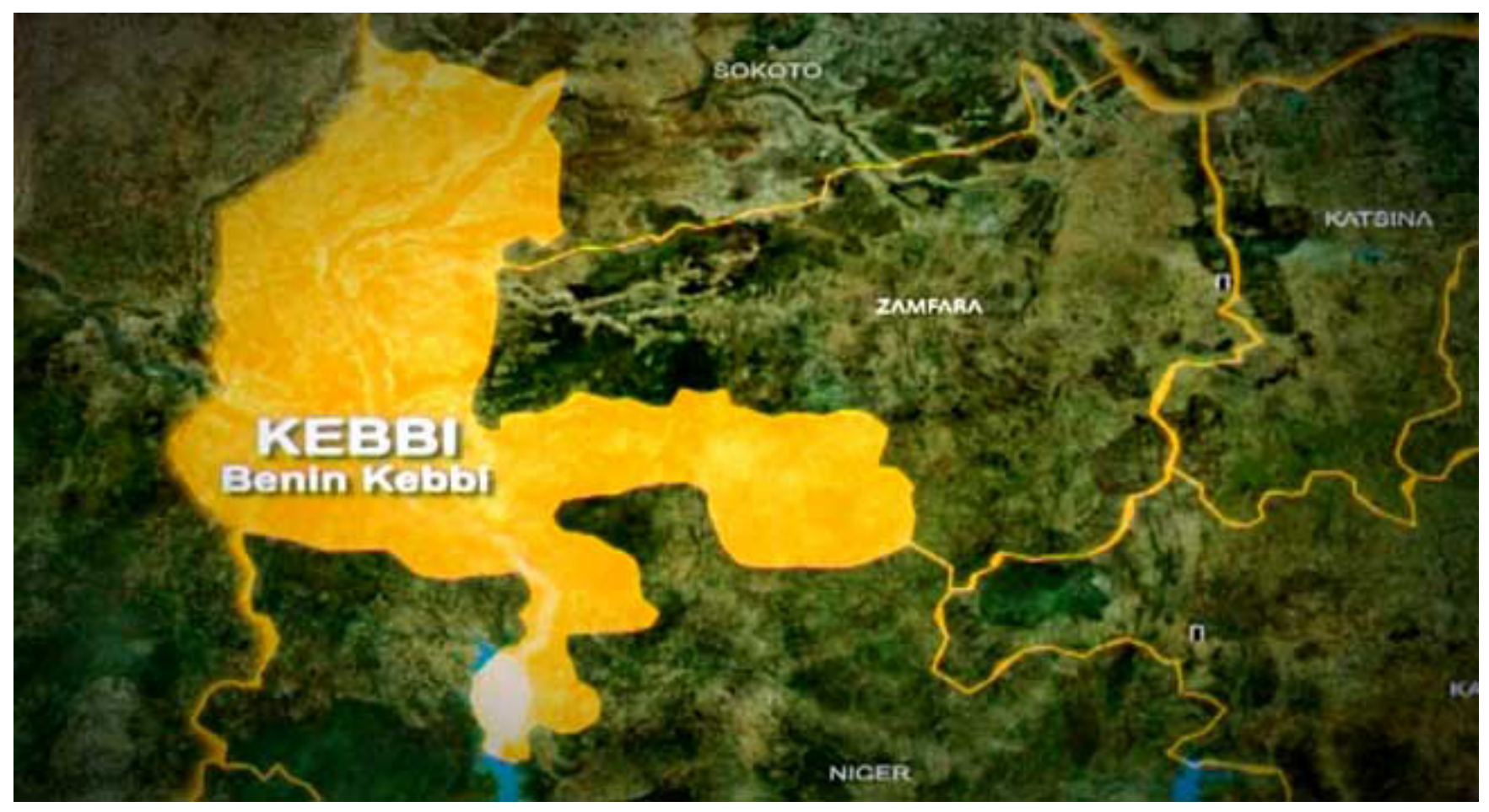

Figure 3.0: Map of Kebbi State, Nigeria

\subsection{Method of Data Collection}

Survey method of data collection was conducted by the World Bank in the collection of data from 3976 household in the rural communities in Kebbi, Nigeria. 4 variables were extracted from the original dataset to form a new dataset (Kebbi.csv).Below are the description of the extracted variables.

\subsubsection{Variables}

-Employed_members: These are a numeric data describing how many members of the household in Kebbi worked in a business or in a self-employment in the past 12 month which is ranked $($ No $=0$, Yes $=1)$ to determine the number of members of each household is employed.

-Annual_income: These are numeric data on annual income of households ranked from 1 Naira (N1) to 20 Naira (N20) which is used to grade income level. Naira is the currency name for Nigeria with symbol (N).

To determine the deforestation rate which one of its courses is the use of fuel wood and charcoal for source of energy for domestic (cooking, lighting, ironing), commercial (ironing, bakery, street fast food) and economic gain (selling of fuel wood and charcoal) purposes by households, the following variables were also analyzed.

-Lighting_fuel_source: Ranked from 1 to 10 in the category of collected firwood, purchased firewood, grass, kerosene, phcn electricity, generator, gas, battery, candles, and others.

-Cooking_fuel_source: Ranked from 1 to 9 in the category of collected firewood, purchased firewood, coal, grass, kerosene, phcn electricity, generator, gas, and others.

\subsection{Method of Data Analysis}

Different analytical models were applied to analyze the variables using $\mathrm{R}$ Programming. The frequencies and the mean of each variable were determined respectively by histogram and boxplot. The null hypothesis 
$\left(H_{0}\right)$ was tested using One-Way Analysis of Variance (ANOVA) and will be rejected if $(p<0.05)$.

\subsection{RESULTS AND DISCUSSIONS}

In the process of analyzing the dataset Kebbi.csv having 3976 observations, 269 values were discovered missing and was omitted.

\begin{tabular}{|c|c|c|c|c|}
\hline \#\# & Household & Employed_members & Lighting_fuel_source & Cooking_fuel_source \\
\hline \#\# & Length: 3976 & Min. $\quad: 1.000$ & Min. $\quad: 1.000$ & Min. $\quad: 1.000$ \\
\hline \#\# & Class : character & 1st Qu.: 1.000 & 1st Qu.: 2.000 & 1st $Q u .: 1.000$ \\
\hline \#\# & Mode : character & Median : 1.000 & Median : 5.000 & Median : 1.000 \\
\hline \#\# & & Mean $: 1.274$ & Mean : 5.207 & Mean $: 1.211$ \\
\hline \#\# & & 3rd Qu.:1.000 & 3rd Qu.: 8.000 & 3rd Qu.:1.000 \\
\hline \#\# & & Max. $\quad: 5.000$ & Max. $\quad: 10.000$ & Max. $: 9.000$ \\
\hline \#\# & & NA's & NA's & NA's \\
\hline \#\# & Annual_income & & & \\
\hline \#\# & Min. $\quad: 0.000$ & & & \\
\hline \#\# & 1st Qu.: 5.000 & & & \\
\hline \#\# & Median : 5.000 & & & \\
\hline \#\# & Mean $: 6.809$ & & & \\
\hline \#\# & 3rd Qu.: 8.000 & & & \\
\hline \#\# & Max. $: 20.000$ & & & \\
\hline \#\# & NA's & & & \\
\hline
\end{tabular}

Table 1.0: Summary of the Kebbi.csv dataset

The total number of missing vales omitted is

\#\# [1] 269

A new data frame Kebbitable.1 with 3758 observations was created. The table below is the first twenty column of the of the dataset Kebbitable.1 showing the four variables and the summary.

\begin{tabular}{lrrrr}
\hline Household & Employed_members & Lighting_fuel_source & Cooking_fuel_source & Annual_income \\
\hline Ujariyo/Junju1 & 1 & 5 & 1 & 5 \\
Ujariyo/Junju1 & 1 & 5 & 1 & 5 \\
Ujariyo/Junju1 & 1 & 2 & 2 & 10 \\
Ujariyo/Junju1 & 1 & 2 & 2 & 15 \\
Ujariyo/Junju1 & 1 & 5 & 1 & 10 \\
Ujariyo/Junju1 & 1 & 5 & 1 & 20 \\
Ujariyo/Junju1 & 1 & 5 & 1 & 0 \\
Ujariyo/Junju1 & 1 & 5 & 1 & 0 \\
Ujariyo/Junju1 & 1 & 5 & 1 & 3 \\
Ujariyo/Junju1 & 1 & 5 & 2 & 5 \\
Ujariyo/Junju1 & 1 & 5 & 1 & 15 \\
Ujariyo/Junju1 & 1 & 5 & 1 & 20 \\
Ujariyo/Junju1 & 1 & 8 & 1 & 15 \\
Ujariyo/Junju1 & 1 & 2 & 2 & 10 \\
Ujariyo/Junju1 & 1 & 5 & 1 & 5 \\
Ujariyo/Junju1 & 1 & 5 & 1 & 15 \\
Ujariyo/Junju1 & 4 & 2 & 2 & 10
\end{tabular}




\begin{tabular}{lrrrr}
\hline Household & Employed_members & Lighting_fuel_source & Cooking_fuel_source & Annual_income \\
\hline Ujariyo/Junju1 & 1 & 1 & 1 & 10 \\
Ujariyo/Junju1 & 1 & 5 & 1 & 2 \\
Ujariyo/Junju1 & 1 & 2 & 2 & 10 \\
\hline
\end{tabular}

Table 2.0: First 20 column of the dataset Kebbitable. 1 from 3758 households in Kebbi Nigeria.

\begin{tabular}{|c|c|c|c|c|}
\hline \#\# & Household & Employed_members & Lighting_fuel_source & Cooking_fuel_source \\
\hline \#\# & Length: 3758 & Min. $: 1.000$ & Min. $\quad: 1.000$ & Min. $\quad: 1.000$ \\
\hline \#\# & Class : character & 1st $\mathrm{Qu} .: 1.000$ & 1st $\mathrm{Qu} .: 2.000$ & 1st $Q u .: 1.000$ \\
\hline \#\# & Mode : character & Median : 1.000 & Median : 5.000 & Median : 1.000 \\
\hline \#\# & & $: 1.279$ & Mean : 5.216 & Mean $: 1.215$ \\
\hline \#\# & & 3rd Qu.:1.000 & 3rd Qu.: 8.000 & 3rd Qu.:1.000 \\
\hline \#\# & & Max. $: 5.000$ & Max. $: 10.000$ & Max. $: 9.000$ \\
\hline \#\# & Annual_income & & & \\
\hline \#\# & Min. $\quad: 0.000$ & & & \\
\hline \#\# & 1st Qu.: 5.000 & & & \\
\hline \#\# & Median : 5.000 & & & \\
\hline \#\# & Mean : 6.936 & & & \\
\hline \#\# & 3rd Qu.: 8.000 & & & \\
\hline \#\# & Max. $: 20.000$ & & & \\
\hline
\end{tabular}

Table 3.0 Summary of the dataset Kebbitable.1 and variables.

From the histogram and boxplot results, it revealed that about 3300 households only have one member employed in a business or in a self-employment in the past 12 months with an average mean of 1.28, and 1200 households has an annual income of 5 Naira (N5) which is below average mean income of 7 Naira (N7). 


\section{Employed Members}

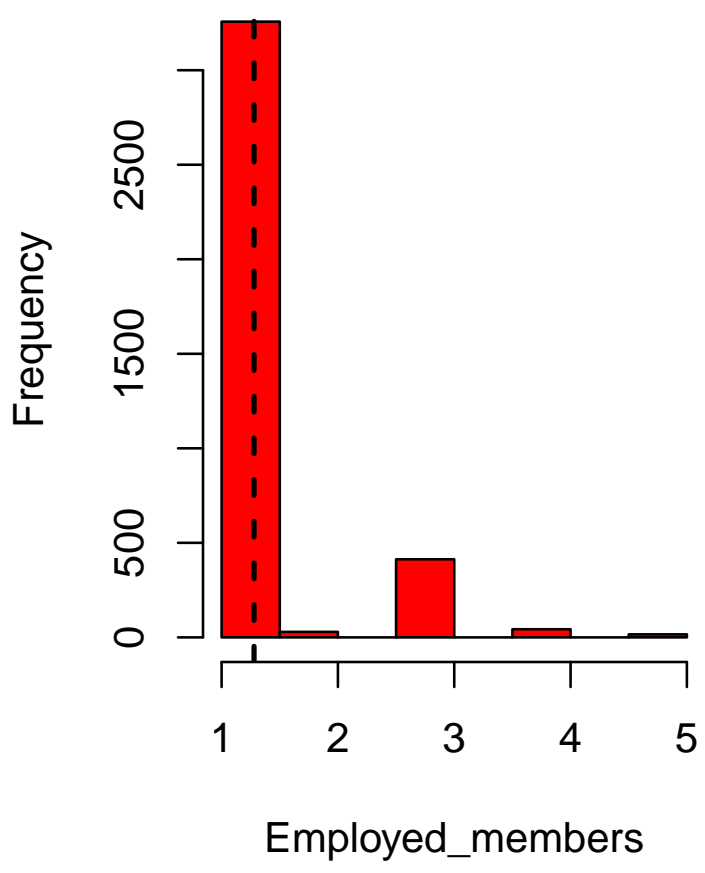

Annual Income

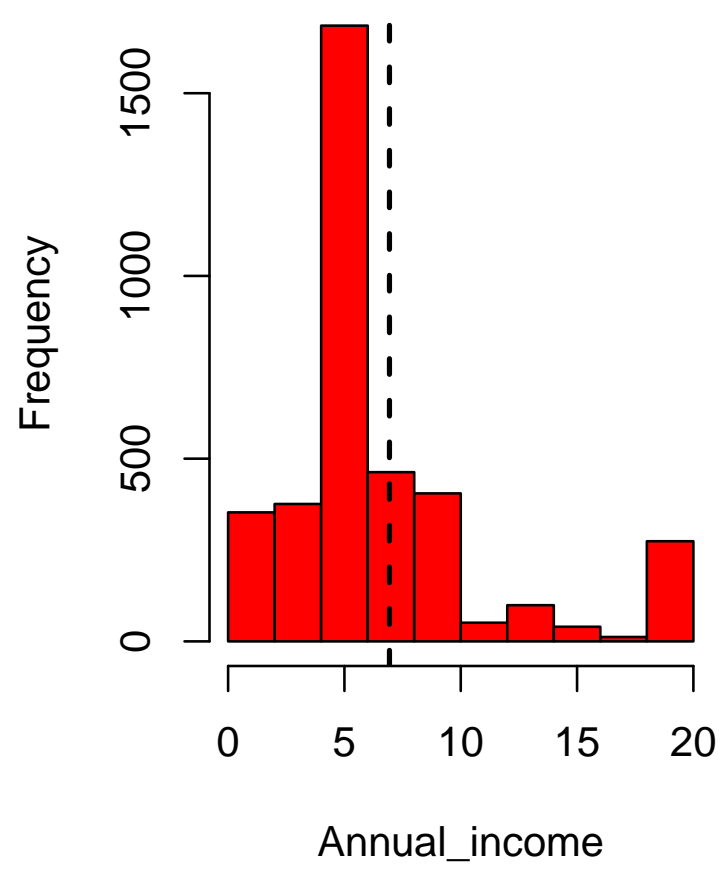


Sources of Lighting Fuel

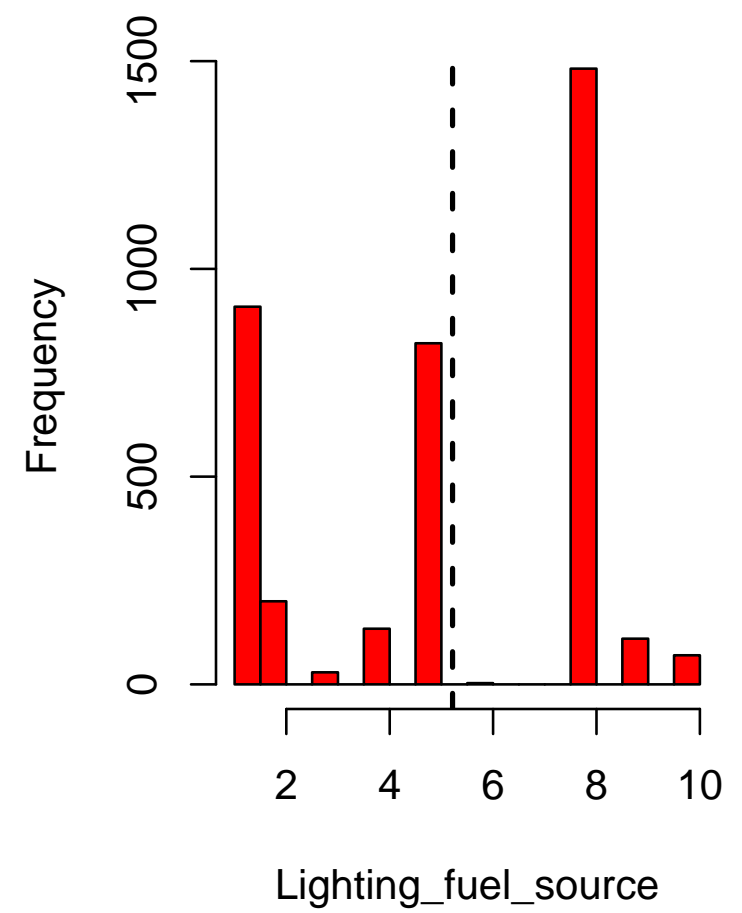

Sources of Cooking Fuel

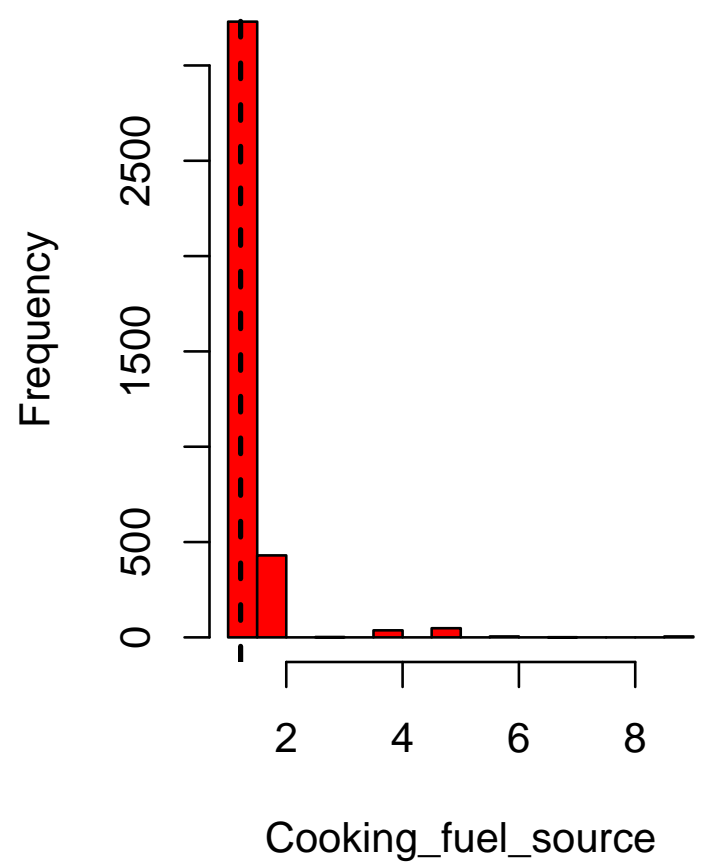

Figure 4.0: Histogram of Employed Members, Annual Income, Lighting and Cooking Fuel Source of the Households in Kebbi, Nigeria.

This proves that over $95 \%$ of the households in Kebbi are low-income earners. In the use of fuel wood (firewood) for the source of energy/fuel by households for domestic and commercial purposes, over $95 \%$ (about 3300 households) of the households in Kebbi use fuel wood for cooking with an average mean of 1.22 and about $40 \%$ use fuel wood for lighting with an average mean of 5.23, though its frequency is nearly equal to members that use electricity as a source of lighting, and $50 \%$ of the households use battery for lighting source. 
Mean of Employed Members

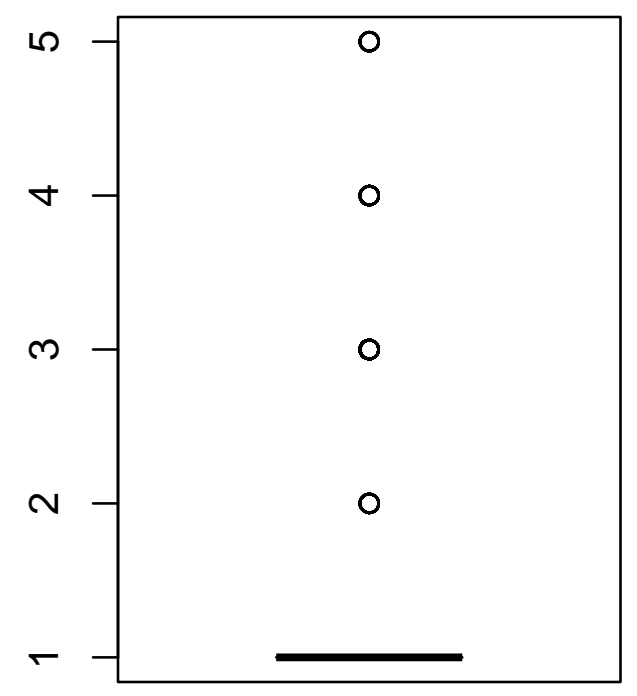

\section{Mean of Annual Income}

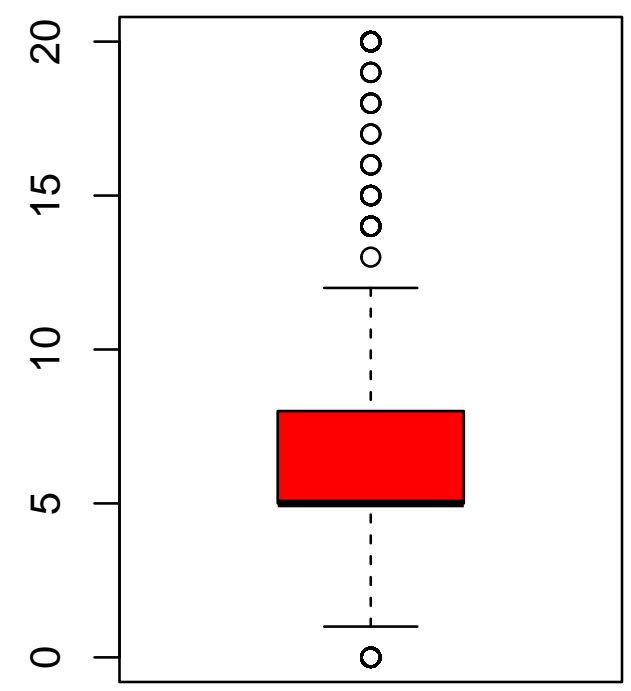

\#\# [1] 1.278872

\#\# [1] 6.936402 


\section{Mean of Sources of Lighting Fue Mean of Sources of Cooking Fue}
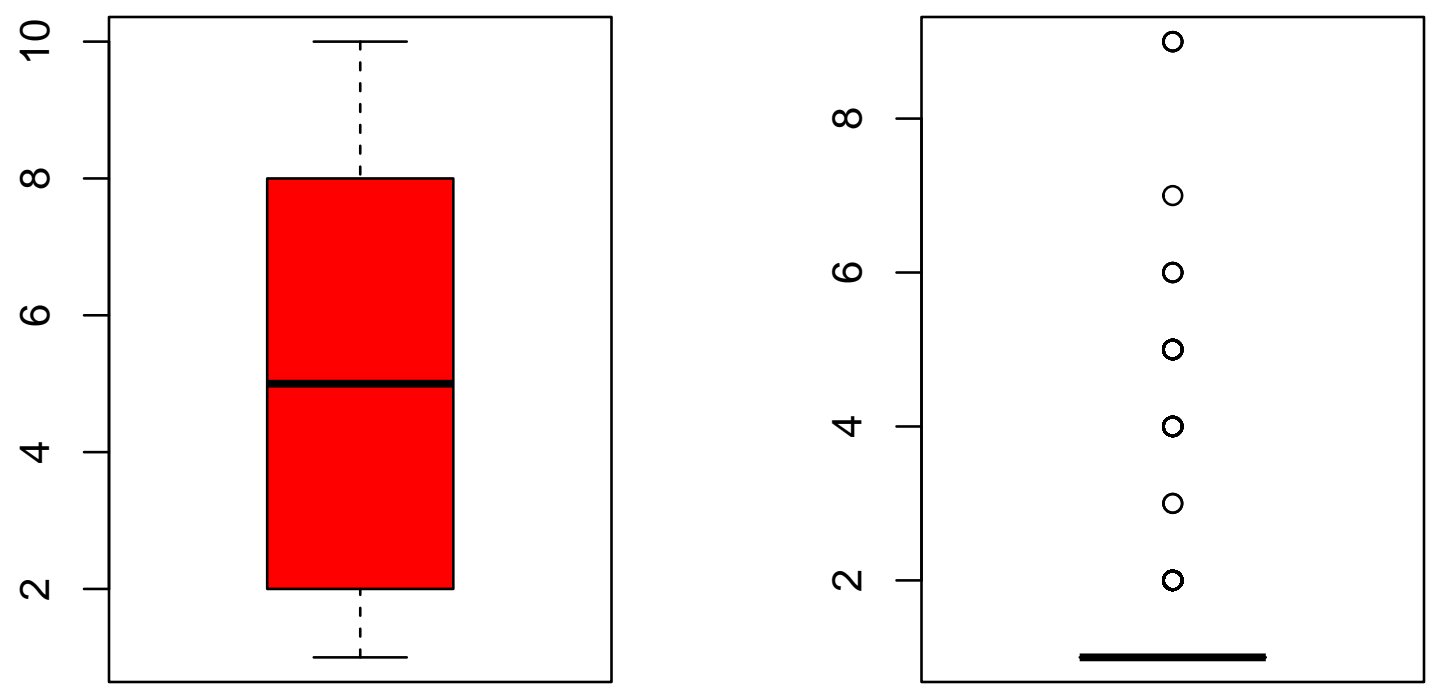

\#\# [1] 5.215806

\#\# [1] 1.215008

Figure 5.0: Boxplot showing mean value for Employed Members, Annual Income, Lighting and Cooking Fuel Source of the Households in Kebbi, Nigeria.

Based on these results, there is high dependence on fuel wood by households for domestic and commercial activities.

According to the test hypothesis, Annual_income has significant impact on Cooking_fuel_source $(0.0104<$ $0.05)$ and has a very strong significant on Lighting_fuel_source $(0<0.05)$. The low-income rate of households was evident showing the relationship between Employed_members with a very strong significant on Annual_income $(0.000375<0.05)$. 
Figure 6.0: employed members vs annual income
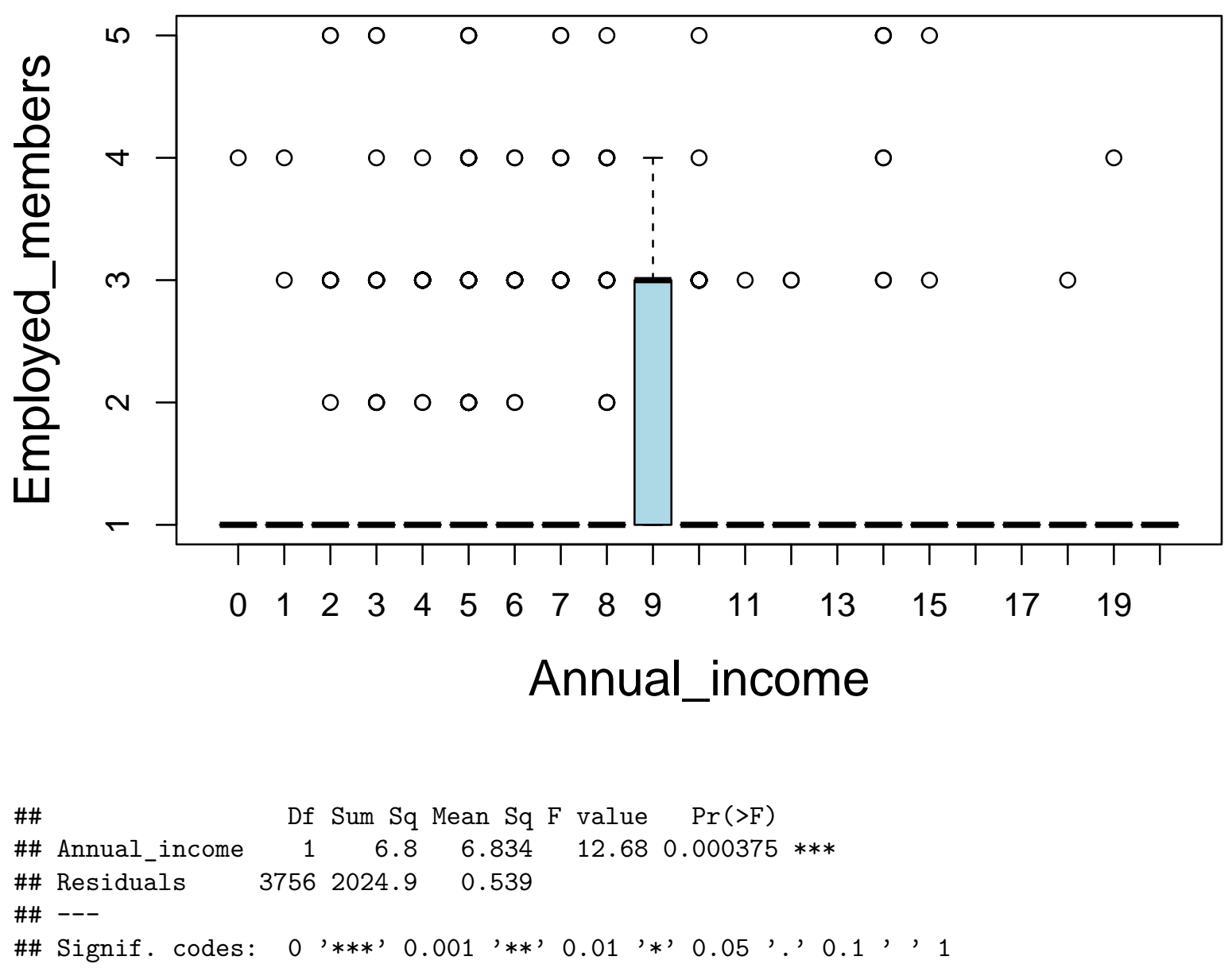

Table 4.0: Summary of ANOVA for Test of the null hypothesis Unemployment rate has no effect on low income. 
Figure 7.0: emplyed members vs cooking fuel

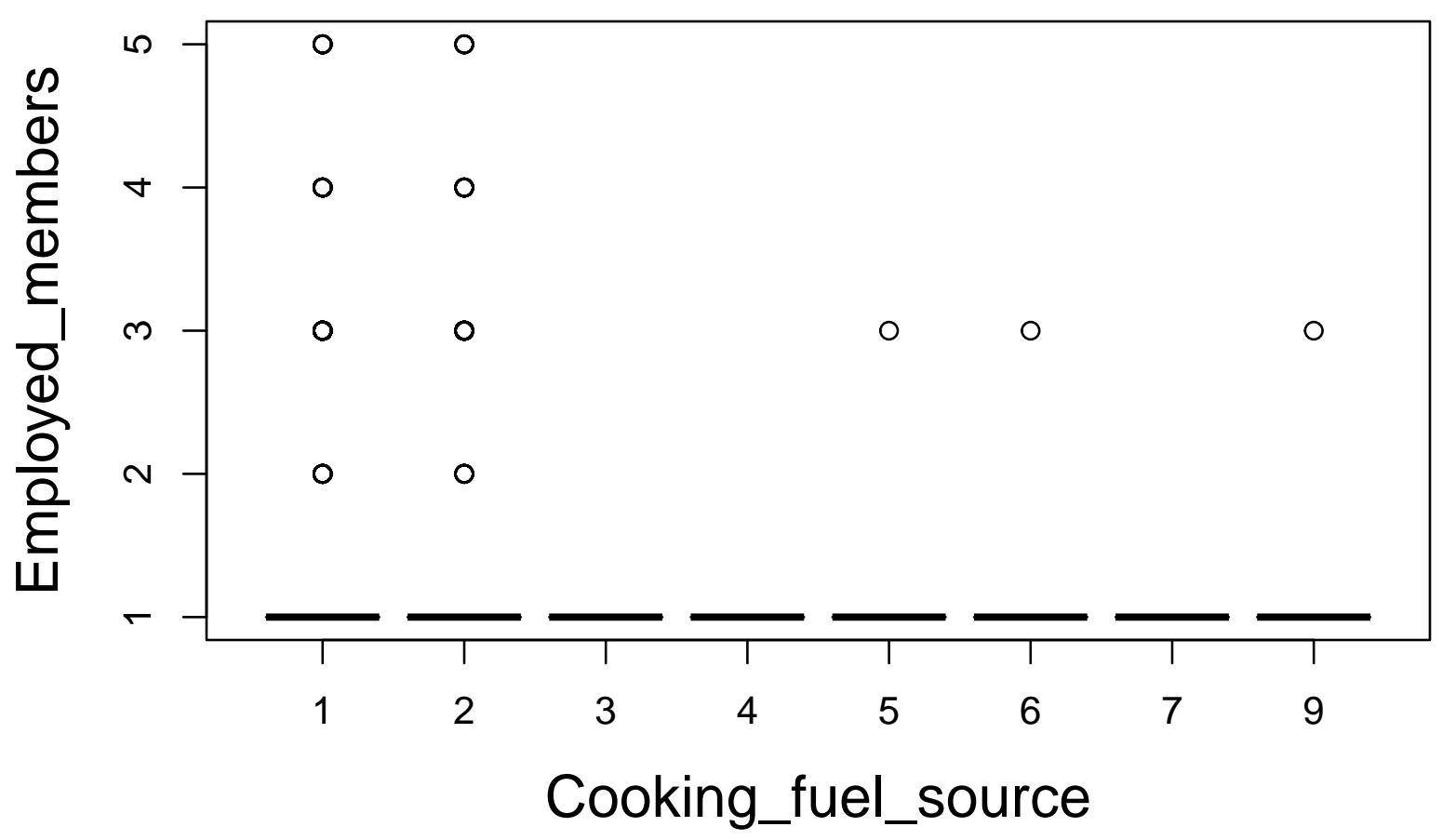




\section{Figure 8.0: emplyed members vs lighting fuel}
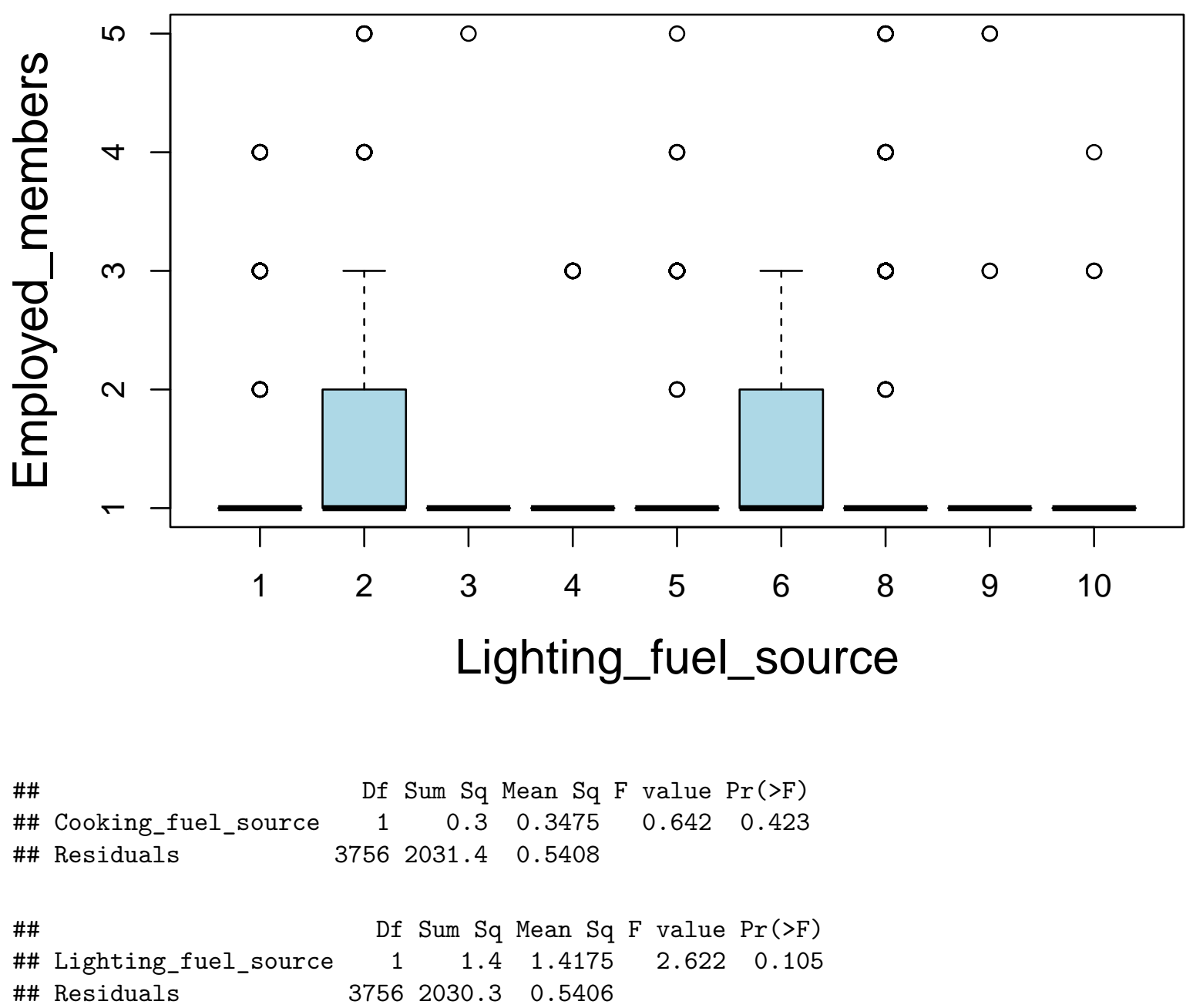

Table 5.0: Summary of ANOVA for Test of the null hypothesis Unemployment rate has no effect on deforestation (Cooking and Lighting Fuel Sources). 
Figure 9.0: annual income vs lighting fuel

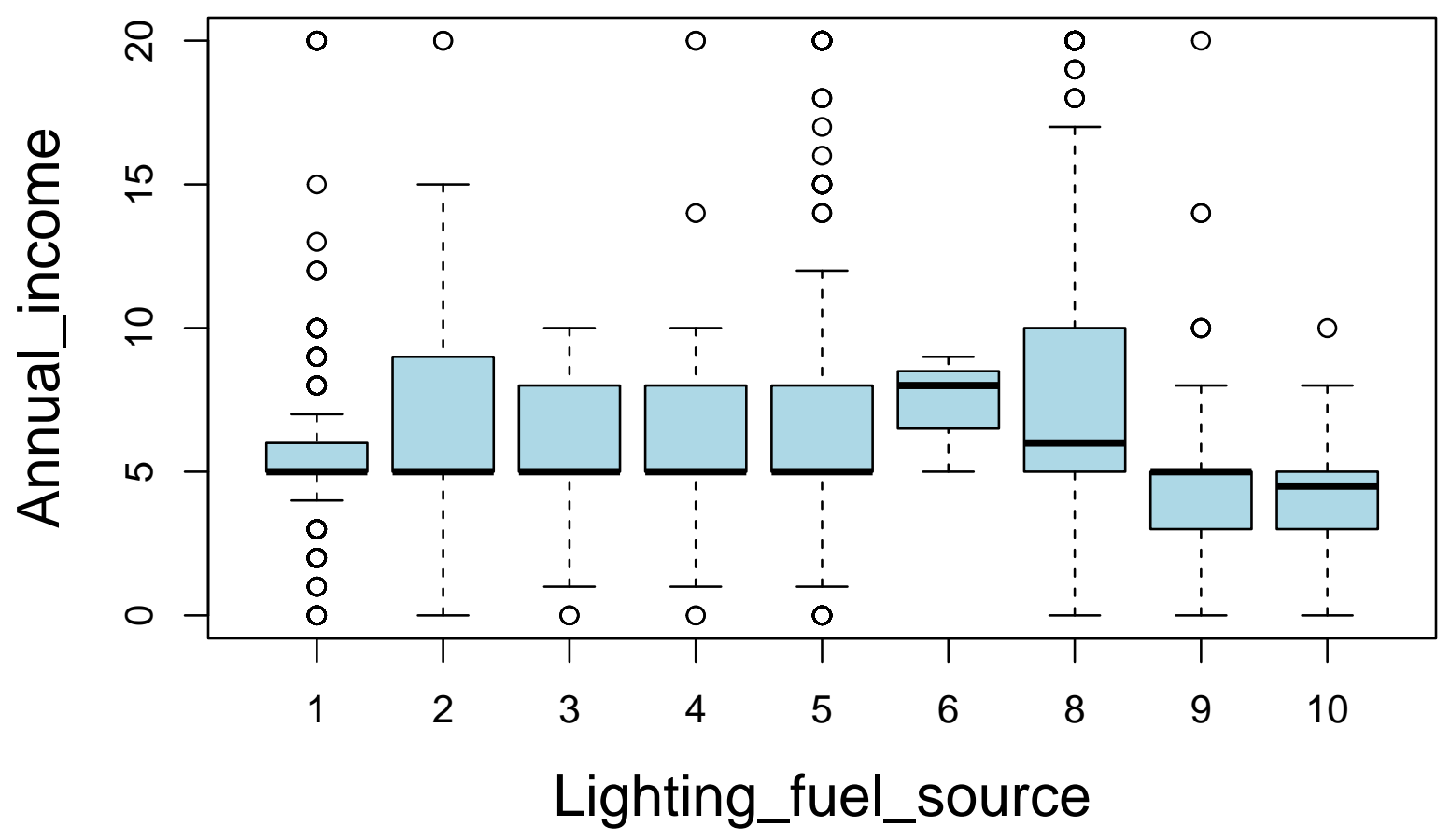




\section{Figure 10.0: annual income vs cooking fuel}
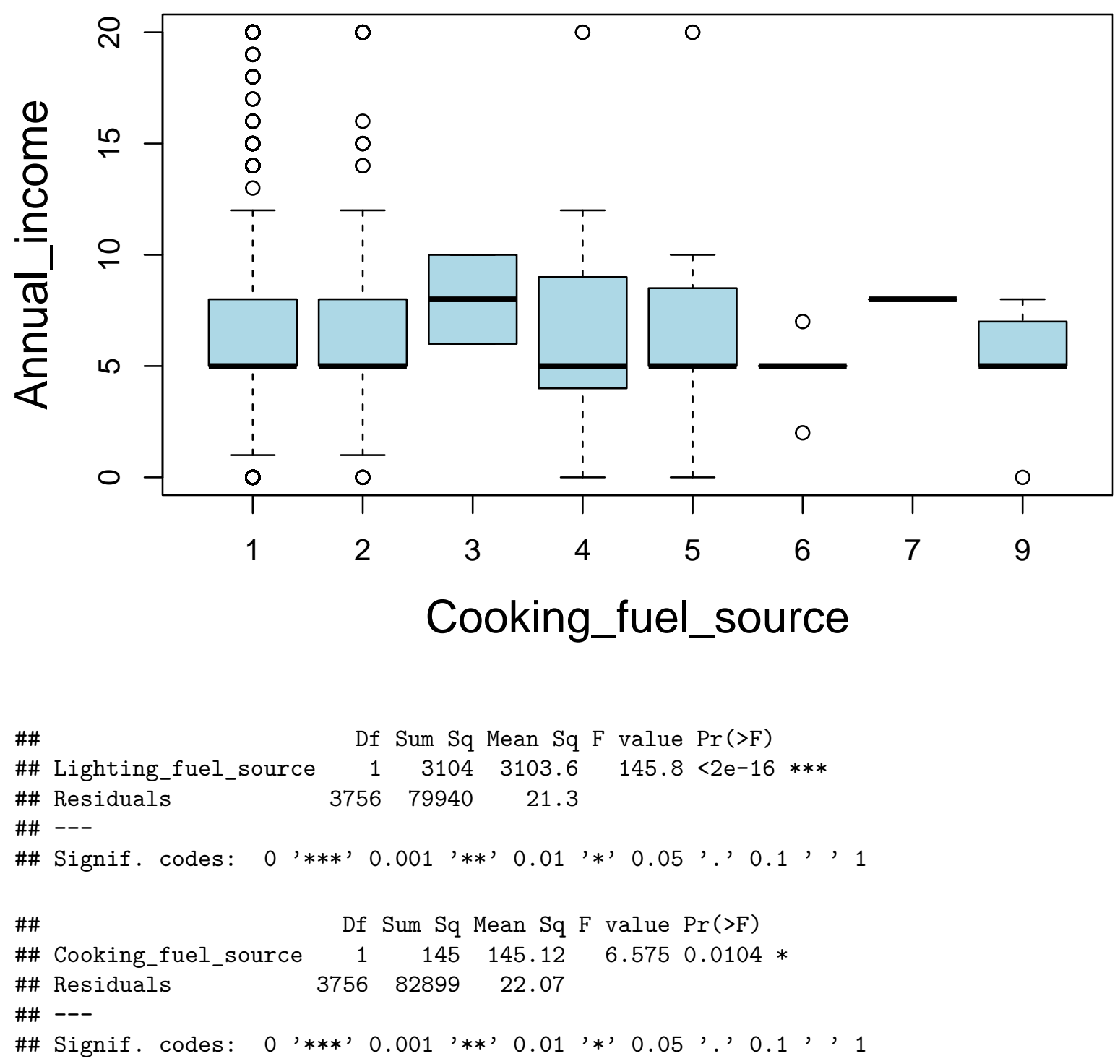

Table 6.0: Summary of ANOVA for Test of the null hypothesis Low income has no effect on deforestation (Cooking and Lighting Fuel Sources).

This revealed that unemployed members of households result to low income of the households in Kebbi, makes them to highly depend on the use of fuel wood (firewood) on daily bases for both domestic and commercial purposes. Therefore, the null hypothesis was all rejected.

Limitations: This research is limited to the use of fuel wood for cooking and lighting purposes by household.

\subsection{CONCLUSION}

High rate of unemployment among household members in Nigeria which results to their low-income state, are highly dependent on falling of tress for source of energy for domestic and commercial purposes and are 
not able to utilize other source of energy because of their low-income state. This situation and practice have a negative effect on tree cover resulting to deforestation and over time will be the most anthropogenic course of deforestation in Nigeria. Tree covers as a medium of carbon sinking is very important in reducing $\left(\mathrm{CO}_{2}\right)$ concentration in the lower atmosphere, which is a major course of global warming. Tree covers are also natural habitat for animal species and elimination of trees can lead to loss of biodiversity of plant and animal species. Trees are also a good protection of top soil good for cultivation from erosion. Therefore it is important the causative factors like unemployment and low-income rate among members of households be address in order to reduce the rate of deforestation in Nigeria.

\section{Recommendations}

-Adequate education on the impact of the use of fuel wood as a source of energy should be taken to households in Nigeria.

-Other sources of energy should be made available to household at a subsidized rate so that low-income earners can make utilize them.

-Government should create more job opportunities to reduce the rate of unemployment.

\subsection{REFERENCE}

1. Aboh, P.Z. \&Zhanggi, W. (2016). Charcoal and Fuelwood Consumption and Its Impact on Environment in Cote d' Ivoire (Case Study of Yopougon Area) [PDF file]. Environmental and Natural Research: 6(4), 34. Retrieved from DOI: 10,5539/enrr.v6n4p26

2. Habila, S. K. (2018). Deforestation in Nigeria: A Critical Assessment of the Church of Christ in Nation's (COCIN) Community Development Programe (CCDP) on Ecology in Panyam District, Mangu Local Government Council, Plateau State [PDF file]. Research Space: 18-30. Retrieved from https: //www.researchspace.ukzn.ac.za/handle/10413/17010

3. Hasan, V. O. (2020). Deforestation. ResearchGate: 2. Retrieved from DOI: 10.1007/978-3-319-74336$3 \_390-1$

4. Patrick, N. (2013). Comparative Analysis of Domestic Energy Use in Nigeria - A Review [PDF file]. ResearchGate: 10-12. Retrieved from DOI: 10.5707/cjre.2013.4.1.7.17

5. Ogunsanwo, O.Y., Altah, V. I., Adenaiya, O. A. and Umar, M. (2018). Sustainable Uilization of Firewood as a Form of Energy in Nigeria. ResearchGate: 5. Retrieved from https://www.researchgate.net /publication/328930229

6. World Bank (2015). Nigeria - Feed the Future Nigeria Livelihoods Project 2015, Baseline Survey (worldbank.org). World Bank Microdata Library. Retrieved from https://microdata.worlbank.org/ index.php/catalog/2935/get.microdata 